groups may be affected more than others, particularly elderly people and those on low incomes, who may have the greatest need for health care. ${ }^{13}$

Inequalities of access may also result from variations in people's inclination to seek help, which is influenced by culture and geography. Perceived need, for example, has been found to relate inversely to remoteness. ${ }^{14}$ How much such barriers to access affect health outcomes in Britain is unknown. A recent study of colorectal cancer in France found that a lower proportion of the rural population than urban populations was treated in specialised health centres and that rural women were diagnosed later and had a worse prognosis than urban women. ${ }^{15}$

The costs of providing services in rural areas are usually higher because economies of scale are lacking and travel costs are higher. ${ }^{16}$ The NHS does not have a consistent policy about whether to take rurality into account when allocating resources. Scotland and Wales use a sparsity weighting when allocating resources to community health care, but the Department of Health and English health authorities do not. Rurality is taken into account throughout Britain when general practice is funded but not at all when resources for hospital services are allocated. The NHS Management Board, when reviewing the Resource Allocation Working Party formula, acknowledged that some sparsity factor may be justified in allocating resources. It noted the methodological difficulties and concluded that more research was needed. ${ }^{17}$ In addition to considering how "need" varies such research should consider how the unit costs of health care differ between rural and urban environments.

Deprivation indices, as proxies for health need, are increasingly being used to allocate resources, and it is important that such measures are validated for rural use. Their use in comparing the social problems of urban and rural areas has been criticised on the grounds that most commonly used indices have been designed for urban populations and may fail to capture the real nature of rural deprivation. ${ }^{18}$ For example, the meaning of car ownership-a variable frequently incorporated in indices-will differ in rural and urban settings. The relation between self reported morbidity and indices of deprivation has been shown to break down in non- metropolitan areas. ${ }^{19}$ Employment is declining and homelessness increasing faster in rural areas than in towns. ${ }^{20}$

The popular imagery of the rural idyll has hindered the questioning of received wisdom that life is better in the country than the city. It's time to end the comparative neglect of rural health. Senior registrar ANTONY J FRANKS Senior lecturer

Academic Unit of Public Health Medicine,

University of Leeds,

Leeds LS2 9NL

TREVOR A SHELDON Senior Research Fellow

Centre for Health Economics,

University of York,

York YO1 5DD

1 Fearn R. Rural health care: a British success or a tale of unmet need? Soc Sci Med 1987;24:263-74 2 Cater J, Jones T. Social geography - an introduction, to contemporary issues. London: Edward Amold, 1989.

3 Office of Population Censuses and Surveys. Area morality: decennial supplement 1969-73, England and Wales. London: HMSO, 1981.

4 Office of Population Censuses and Surveys. Morality and geography. A review in the mid 1980s, England and Wales. London: HMSO, 1989.

England and Wales. London: HMSO, 1989.
Chilvers C. Regional mortality 1969-73. Population Trends 1978;11:16-20.

5 Chilvers C. Regional mortality 1969-73. Population Trends 1978;11:16-20.
6 Bentham GG. Mortality in the more rural areas of England and Wales. Area 1984;16:219-26.

7 Office of Population Censuses and Surveys. Morbidity statistics from general practice. Third national study 1981-82. London: HMSO, 1989.

8 Haynes R, Bentham G. The effects of accessibility on GP consultations; out-patient attendances and in-patient admissions in Norfolk, England. Soc Sci Med 1982;16:561-9.

9 Phillimore P, Reading R. A rural advantage? Urban-rural health differences in northern England. $f$ Public Health Med 1992;14:290-9.

10 Lievesley K, Maynard W. 1991 survey of rural services. London: Rural Development Commission, 1992.

11 Parkin D. Distance as an influence on demand in general practice. $f$ Epidemiol Community Health 1979;33:96-9.

12 Haynes RM, Bentham CG. Accessibility and the ue of hospitals in rural areas. Area 1979;11:186-91. 13 Bentham CG, Haynes R. A raw deal in remoter areas? Family Practitioner Services 1986;13:84-7.

14 Bloor M, Horobin G, Taylor R, Williams R. Island health care: access to primary services in the Westerm Isles. Aberdeen: Institute of Medical Sociology, University of Aberdeen, 1978. (Occasional paper Isles. Aberdeen: Institute of Medical Sociology, University of Aberdeen, 1978. (Occasional paper No 3.)

15 Launoy G, Le Coutour X, Gignoux M, Pottier D, Dugleux G. Influence of rural environment of diagnosis, treatment, and prognosis of colorectal cancer. $\mathcal{f}$ Epidemiol Community Health 1992;46:365-7.

16 Woollett S. Counting the rural cost: the case for a rural premium. London: National Council for Voluntary Organisations, 1990.

17 Department of Health and Social Security. Report of the Resource Allocation Working Party formula: final report by the NHS Management Board. London: DHSS, 1988.

8 Knox P. Disadvantaged households and areas of deprivation: microdata for the 1981 census of Scotland. Environment and Planning A 1985;17:413-5.

19 Jessop EG. Individual morbidity and neighbourhood deprivation in a non-metropolitan area. $f$ Epidemiol Community Health 1992;46:543-6.

20 Lambert C, Jeffers S, Burton P, Bramley G. Homelessness in rural areas. Salisbury: Rural Development Commission, 1992. (Rural research series No 12.)

\title{
Home treatment for acute psychiatric disorder
}

\author{
May be better, but inpatient facilities are still needed
}

The government's plan for providing more care in the community ${ }^{1}$ has revived interest in treating patients with acute psychiatric illness at home. Potential conditions for home treatment include serious mental illness (such as schizophrenia and affective psychosis) and exacerbations of neurotic conditions.

Although some general practitioners have been doing this for years, specialist psychiatric services have moved out from their hospital bases only over the past 20 years. The first such services in Britain offered "crisis intervention"2psychotherapeutic help provided by mobile teams-but they lack systematic evaluation. ${ }^{3}$

In the United States Stein and Test established the "assertive" approach to community treatment. ${ }^{4}$ This consisted of home based assessment and treatment by multidisciplinary teams, who visited as required. Patients (half of them schizophrenic) received this form of care for 14 months, and when these patients were compared with a conventionally treated group symptoms, social functioning, satisfaction with life, employment, and drug compliance all improved and their use of psychiatric beds fell. Economic costs and the burden on family and community were comparable between the two groups. These gains were not sustained after assertive community treatment was withdrawn.

An Australian study over 12 months reported similar gains and also claimed that home treatment was $26 \%$ cheaper than conventional treatment and aftercare. ${ }^{5}$ This study was influential in changing the pattern of services in parts of Australia, where home treatment teams are now well established. A replication study was carried out in the United States, although for much longer, using staff trained by Stein and Test's team. It found, however, that gains made by patients after 30 months were not sustained at five years. ${ }^{6}$

Two recent studies have evaluated 24 hour home treatment 
services in Britain. Working in an inner city area of Birmingham with a group of patients suffering from "severe acute psychiatric illness" (a quarter of them schizophrenic), Dean and Gadd found that the social characteristics of the patient and referral were more likely than illness factors (such as diagnosis) to determine who could be treated at home. Admission was required in one third of cases. Although the area was deprived, social cohesion among the mainly Asian population may have been high. The admission rate of 0.9 per year per 1000 population has been achieved in comparable areas without the benefit of 24 hour teams. ${ }^{8}$

A study by Muijen and colleagues reported on home based treatment in a deprived part of London. ${ }^{9}$ A three year randomised controlled trial compared home care with standard hospital care and follow up for patients described as "seriously ill facing immediate admission," $42 \%$ of whom were compulsorily detained under the Mental Health Act. Results have been reported for the first 189 patients. Patients randomised to home treatment were admitted to hospital, although they spent on average one fifth as long in hospital as the control group. This difference was especially pronounced for neurotic patients. When admitted, patients randomised to home treatment used proportionately more of the hospital's intensive care facilities, which has obvious implications for costs. Psychotic patients received an average of 100 hours of professional contact and neurotic patients an average of 46 hours. On various measures of clinical and social outcome there were no significant differences between the groups.

Two studies from the United States have evaluated intensive management in the community for patients with high psychiatric morbidity and frequent previous admissions to hospital. Wright et al found $80 \%$ less bed use and significantly reduced numbers of prison sentences, cost of community support services, and distress sustained over four years. ${ }^{10}$ Borland et al similarly found an $80 \%$ fall in admissions to hospital over five years, although the number of days in hospital was only $56 \%$ fewer by year $5 .{ }^{11}$ Over this time the number of days in non-hospital residential care (for example, staffed hostels) increased by $280 \%$. The authors noted that the turnover of case managers was "higher than anticipated," and the only member of staff to stay for the duration of the project was the psychiatrist-project leader. Although not suggested by the authors, this may indicate difficulty in sustaining assertive community service for a prolonged period and the burnout of members of staff.

The community support treatment and rehabilitation programme (COSTAR), a mobile treatment and case management service in deprived inner city Baltimore, shows how subtle the gains may be for patients. ${ }^{12}$ Patients in long term contact with the service showed better social functioning and wider social networks but no change in symptoms or cognitive or global function. The authors concluded that home based treatment can help patients replace social isolation with supportive social contacts.

A British study compared patterns of use of services as provision changed from a traditional mental hospital to a district general hospital, with conventional community services including a day hospital and day centres. ${ }^{13}$ Over the 14 years of the study the new community resources did not reduce the demand for hospital beds, and the average length of stay, readmission rate, and accumulation of new long stay patients remained unchanged. The authors concluded that "there is a bed-rock of illness which will always need inpatient care however comprehensive the community resources."
A similar conclusion may be drawn from an evaluation of the Italian psychiatric reforms, which virtually closed many psychiatric hospitals at a stroke. ${ }^{14}$ In South Verona, one of the few places to provide a full range of community services, the number of admissions to all inpatient psychiatric facilities (including private hospitals) was only $8.4 \%$ lower in 1988 than in 1977 (a year before the reforms), although the number of occupied beds was $47 \%$ lower.

The risk of suicide needs specific mention. Most studies of short term home care have not reported any increase in suicide, but a worrying finding of the study of Muijen and colleagues was that two suicides occurred and a patient was charged with homicide in the group allocated to home treatment. Suicides of patients in regular contact with community programmes are, however, more likely to be picked up than those of patients who merely default from outpatient follow up.

Most studies therefore seem to favour home treatment over conventional inpatient treatment for acutely ill psychiatric patients, particularly when measured by acceptability to the patient and relatives and by social functioning. Costs seem about equal. The benefits seem to fall the longer the study continues-perhaps indicating burnout among staff. Many patients will still need admission to hospital at some point, although this is usually quite brief. More recent studies show less clear cut differences, perhaps because the distinction, between the services is blurring as conventional services begin to offer more assertive outreach.

Can research findings be generalised to everyday provision of services? Studies usually recruit motivated staff, who perform with zeal for the finite duration of the study; this may contrast with the attitudes of staff providing a routine service. And patients may differ from those reported on in these studies, which excluded patients with drug or alcohol problems, organic mental disorders, and learning disabilities. Some of the American studies used laws, such as community treatment orders, that are not available in Britain at present.

In the light of current studies, home treatment for acute psychiatric conditions can be a useful constituent of a comprehensive mental illness service. Whether it can fully replace the functions of the acute psychiatric inpatient unit has not been established.

\section{PAUL DEDMAN} Consultant psychiatrist

United Bristol Healthcare Trust,

Barrow Hospital,

Barrow Gurney,

Bristol, BS19 3SG

1 Department of Health and Social Security. Caring for people. London: HMSO, 1989

2 Caplan G. Principles of preventive psychiatry. London: Tavistock Publications, 1964

3 Scott RD. A family orientated psychiatric service to the London borough of Barnet. Health Trends 1980;12:65-8.

4 Stein LI, Test MA. Alternative to mental hospital treatment. 1. Conceptual model, treatment program, and clinical evaluation. Arch Gen Psychiatry 1980;37:392-7.

5 Hoult J, Reynolds I. Schizophrenia: a comparative trial of community orientated and hospital orientated psychiatric care. Acta Psychiatr Scand 1984;69:359-72.

6 Mulder R. Evaluation of the Harbinger program, 1982-1985. Lansing: Michigan Department of Mental Health, 1985.

7 Dean C, Gadd EM. Home treatment for acute psychiatric illness. BMF 1990;301:1021-3.

8 Hamilton M, Lee AS. Home treatment for acute psychiatric illness. BMF 1991;302:49.

9 Muijen M, Marks I, Connolly J, Audini B, McNamee G. Home based care and standard hospital care for patients with severe mental illness: a randomised control trial. $B M$ I 1992;304:749-54.

care for patients with severe mental illness: a randomised control trial. $B M \mathcal{F}$ 1992;304:749-54.
10 Wright RG, Heiman JR, Shupe J, Olvera G. Defining and measuring stabilization of patients right RG, Heiman JR, Shupe J, Olvera G. Defining and measuring stabilization
during 4 years of intensive community support. Am $f$ Psychiatry 1989;146:1293-8.

11 Borland A, McRae J, Lycan C. Outcomes of five years of continuous case-management. Hosp Community Psychiatry 1989;40:369-76.

12 Thornicroft G, Breakey WR. The COSTAR programme. I. Improving social networks of the longterm mentally ill. Br f Psychiatry 1991;159:245-9.

13 Lawrence RE, Copas JB, Cooper PW. Community care: does it reduce the need for psychiatric beds? Br F Psychiatry 1991;159:334-40.

14 Tansella M, ed. Community-based psychiatry: long-term patterns of care in South-Verona. Psychol Med Monogr Suppl 1991;19 (abstract). 